PPPL -2539

DE88 015863

\section{CORRECTIONS TO CHARGE EXCHANGE SPECTROSCOPIC MEASLREMENTS IN TFTR DUE TO ENERGY-DEPENDENT EXCITATION RATES}

\author{
R.B. Howell, R.J. Fonck, R.J. Knize, and K.P. Jaehnig \\ Plasma Physics Laboratory, Princeton University \\ Princeton, NJ 08543
}

\begin{abstract}
The use of charge exchange spectroscopy to determine plasma rotation speeds and ion temperature is complicated by the energy dependence of the excitation cross sections. The Dopplin-brandened spectral line shape is distorted by the relative velocity between the neutral hydrogen atoms of the injected beam and impurity ions. The asymmetric nature of the energy dependence of this cross section causes a non-motional shift of the line center and a nonthermal change in the line width. These effects vary with the angles between the beam direction, rotation velocity direction, and direction of the viewing sightline. When viewing two neutral beams at different angles on TFTR, the two measurements of $v_{6}(r)$ show discrepancies of about 20 to $30 \%$ with each other. The calculation of the spectral intensity profiles, using the excitation rates available, overcorrects these discrepancies and indicates the need for better excitation coefficients.
\end{abstract}




\section{INTRODUCTION}

The use of charge exchange recombination spectroscopy (CXRS) has recentiy provided radial profiles of both ion temperature and rotation speeds for TFTR.' Prior to this, CXRS measurements of $T_{i}(r)$ and $v_{\phi}(r)$ were obtained on other tokamaks such as DIII, ${ }^{2,3} \mathrm{PBX}^{4-8} \mathrm{PDX}^{7}$ and ISX-B. Given the widespread acceptance c: the CXRS technique for $T_{i}(r)$ and $v_{\phi}(r)$ measurements in hot plasmas, the complex nature of this measurement continues to require much attention to the atomic physics issues of this process. The emphasis in the present study is on corrections that arise from the energy dependence of the charge exchange excitation cross sections in determining the plasma ion temperature and rotation apeed. This issue gains added urgency in light of the very high temperatures and/or rotation speeds obtained in large machines such as TFTR, where the spread of ion thermal speeds is large enough that the charge exchange rate coefficients change appreciably across the speed distribution.

In the CXRS diagnostic method, the plasma is diagnosed internally by observing the emission from the charge exchange reaction between fast neutral atoms and plasma ions

$$
H^{0}+A^{2} \rightarrow H^{+}+\left(A^{2-1}\right)^{*}
$$

The product jons are left in excited states and the emission from these states produces the observed photons. The Doppler broadening of the emitted light gives $T_{i}$, and the Doppler shift gives $v_{\phi}$. The calculated spectral line intensity 
at wavelength $\lambda$ is expressed as

$$
B^{\lambda}=\frac{1}{4 \pi} \sum_{k} \sum_{J=1}^{3}<\sigma(k) v>j \int N_{J}(k) N_{z} d l,
$$

where $<\sigma(k) v>_{\mathcal{J}}^{\lambda}$ is the effective rate coefficient for charge exchange with a neutral atom in the $J^{\text {th }}$ beam component and the $k^{\text {th }}$ quantum state to produce excitation of a transition at wavelength $\lambda_{1} N_{ \pm}$is the impurity species density, and $N_{J}(k)$ is the beam density of the $J^{\text {th }}$ energy component in level k. The sums are over all possible quantum states of the beam atom and the energy components of the beam (i.e., $E_{0}, E_{0} / 2, E_{0} / 3$ for an $H^{0}$ beam). There is also an integration over the length of the emitting region along the optical line of sight. Since the lifetime of the excited state is short, the emission is usually well localized at the position of the beams. Ignoring any atomic fine structure effects and assuming a thermal velocity distribution, the spectral distribution of an emission line, given by integrating the rate coefficient along the direction perpendicular to the line of sight, is

$$
<\sigma v>_{J}^{\lambda}=A \iint d v_{y} d v_{x} \sigma_{e x}\left(\left|\bar{v}-v_{B}\right|\right)\left|\vec{v}-v_{B}\right| e^{-\left|\bar{v}-v_{\phi}\right|^{2} / \sigma_{\text {IM }}^{2}}
$$

where the sightline is assumed to be along the $x$-axis. The charge exchange excitation cross section $\sigma_{e x}$ depends on the relative velocity between the viewed particle velocity, $\vec{v}$, and the beam velocity, $\overrightarrow{v_{B}}$. The particles have a Gaussian distribution whose maximum is shifted from zero by the rotation velocity $\overrightarrow{v_{\phi}} . \sigma_{t h}^{2}$ is given by $2 k T / M$, where $T$ is the ion temperature, $M$ is the ion mass, and $A$ is a normalizing factor.

For sufficiently high ion temperatures and rotation speeds, the energy dependence of the cross section will affect the excitation rate and thus the emis- 
sion spectral shape. As an indictation of the magnitude of the effects of this line profile distortion, for typical conditions in high temperature TFTR plasmas. we estimate that the central $\nu_{\phi}$ derived from direct line measurcuests could differ from the actual values by up to $20-30 \%$, and the $T_{i}$ by about $10 \%$, if the fully mixed excitation rates from Ref. 7 are accurate. Of course, this is just the effect we hope to take advantage of in efforts to measure the high energy alpha particles produced in an ignited plasma, but it must be made as small as possible for the determination of the bulk ion temperature and rotation speeds. In principle, judicious choices of viewing geometry, beam injection angle, and beam species can be made to minimize these distortions of the spectral line shape (e.g., mutually perpendicular beam injection, rotation velocity, and viewing sightline for best temperature measurements). However, such flexibility is usually not available in the experimental conditions, and thus a well-known and characterized effective charge exchange rate coefficient is necessary to determine accurately both the ion temperature and the rotation speed in given experimental conditions.

The knowledge of the effective cross section for a given impurity ion and a specified transition is, at present, based on a patchwork approach of combining theoretical calculations for a few energies with the effects of mixing energy levels due to ion-ion collisions and the motional Stark effects. ${ }^{7}$ Even assuming high quality cross sections were available for the charge transfer for all of the relevant excited states, plasma environmental effects such as levelmixing due to ion-ion collisions, motional and Zeeman mixing, fine structure broadening, and the population of excited states in the neutral atoms, all 
conspire to reduce the level of confidence in purely theoretical corrections to the measured line widths and shifts. Experimentally, however, the validity of the available rate coefficients can be tested by comparing line shapes and shifts obtained from different viewing directions and different beam species mixes under the same plasma conditions. We report here the preliminary results of such an effort on the TFTR tokarnak, where the $n=8-7$ transition of $C^{+5}(\lambda=529.2 \pi m)$ was studied for $T_{i}$ and $v_{\phi}$ measurements.

\section{A. EXPERIMENTAL OBSERVATIONS}

Observations of $T_{i}(r, t)$ and $v_{\phi}(r, t)$ using CXRS are made on the TFTR tokamak with the CHERS multispatial and multispectral imaging spectrometer system. A schematic of the available viewing sightlines is shown in Fig. 1. Charge exchange excited transitions can be observed from the intersection of the sightlines and the high power heating beam ( $55 \mathrm{keV} / \mathrm{amu} D^{0}, 5-6 \mathrm{MW}$ ) or the low power diagnostic beam $\left(60 \mathrm{keV} / \mathrm{amu} H^{0}, \approx 0.5 \mathrm{MW}\right)$. The view of the spectrometer sightline in the plasma center is roughly colinear with the heating beam ( $\approx 34^{\circ}$ angular separation) and the toroidal rotation velocity $\left(-1.2^{\circ}\right)$. The diagnostic beam is viewed from the counter-linear direction with an angle of $\approx 20^{\circ}$ from the perpendicular and roughly colinear $\left(\approx 20^{\circ}\right.$ ) with the rotation velocity direction at the point of beam-sightline intersection. On a given plasma shot, twelve views, or radial positions, along one of the two beams are used for measurement. Comparison of the uncorrected ion temperature and rotation speed (from the raw data line-width and shift) from two beam sources is then made for identical discharges. 
The need for a better quantitative understanding of the line excitation processes is evident from the comparison of $v_{\phi}$ obtained with these two different beam and viewing geometries. Figure 2 shows such a comparison of the uncorrected values of $v_{\phi}(r)$ for a strongly rotating plasma in TFTR. Tbe $v_{\phi}$ deduced from the view of the DNB was on average higher than the $v_{\phi}$ deduced from the heating beam view, when the speed exceeded about $2.0 \times 10^{5}$ $\mathrm{m} / \mathrm{sec}$. As will be discussed below, this difference is in the direction expected when the estimated rate coefficients, viewing geometries, and beam sperjes are considered. But even with correction for the energy dependence of the excitation rate, a disagreement remains between the $v_{\phi}$ measurements.

\section{B. CALCULATION OF $V_{\phi}, T_{i}$ CORRECTIONS}

An illustration of the effect of the energy dependence of the effective rate coefficient is given in Fig-3a, which shows the evaluation of the line profile via Eqs. (2) and (3) for parameters typical of TFTR plasmas. The values of $\sigma(E) v$ are taken from the unified distorted wave approximation (UDWA) values plotted in Ref.7 under the assumption of full l-mixing in the $n=8$ state of $C^{+5}$. This $\sigma(E) v$ curve is shown in Fig.4. The calculated profiles in Fig.3a represent the extreme case where the viewing sightline, beam velocity, and plasma rotation velocity are all all colinear. For comparison, the other extreme is shown in Fig.3b where the beam direction is at right angles to the sightline, and there is very little shift between the centers of the beam components. The beam density fractions were taken to be 0.47:0.29:0.24 for the $E_{0}, E_{0} / 2, E_{0} / 3$ components, respectively. These values are indicative of 
the species mix expected near the center of the plasma column.

In making these intensity profile calculations, only the ground state of the beam atom was used. The recent work by Isler and Olsen ${ }^{10}$ indicates the charge exchange rate of $C^{+\infty}$ by $n=2$ hydrogen atoms at $20 \mathrm{keV}$ can be as much as two orders of magnitude larger than the excitation rate of $C^{+6}$ by $n=1$ hydrogen atoms at $40 \mathrm{keV}$. Thus, even with excited state populations of the beam atoms on the order of $1 \%$ of the ground state populations, there can be a contribution from them to the $C^{+5}$ excited state populations in the energy range of $\leq 20 \mathrm{keV}$.

The calculations of the corrections to $T_{i}$ and $v_{\phi}$ used the excitation rate shown in Fig.4 from Fonck's earlier work. ${ }^{7}$ A standard beam attenuation codeg (with no multistep processes included) is used to estimate the beam species mix as a function of radius in the plasma. Using these beam density fractions, and beam energies, the methodology consists of calculating "measured" $v_{\phi}$ and $T_{i}$ resulting from "real" $v_{\phi}$ and $T_{i}$ values, and observation angles for the two beams. These corrected values are plotted in Fig.5 for the data in Fig.2. If the effective rate coefficient had the correct energy dependence, the corrected values from the two views should coincide. However, the unmodified UDWA rates appear to overcorrect the HB data when the $v_{\phi}$ exceeds about $4.0 \times 10^{5} \mathrm{~m} / \mathrm{sec}$. The corrected HB and DNB values could show better agreement if we assumed that the actual rate coefficients at low energies (i.e., $\mathrm{E} \leq 40 \mathrm{keV} / \mathrm{amu}$ ) were larger than those shown in Fig.4. This assumption is reasonable given the unreliability of the UDWA cross sections at low energy and our neglect of excited neutrals in the beam. At present, 
it suffices to say that the remaining disctepancy between the corrected $v_{\phi}(r)$ values for the two beams indicates the energy dependence of the excitation rate curve is not adequately well known.

Given the importance of these observations in increasing confidence in the line profile measurements via CXRS, further systematic studies with different neutral atomic species, impurity ion species, and atomic transitions, along with more detailed theoretical estimates, are planned to provide reasonably accurate and reliable corrections to measured $T_{i}$ and $v_{\phi}$ values over a wide range of plasms parameters.

\section{CONCLUSIONS}

The measurments oi $T_{i}$ and $v_{\phi}$ from two different viewing positions on TFTR provide a means of assessing the influence of the charge exchange excitation rate and its energy dependence. A calculation is made of the corrections due to this energy dependence for a typical radial profile of toroidal rotation and ion temperature. The present form of the excitation rate overcorzects the rotation velocities as measured from the two different views. This study focuses on the $n=8$ to $n=7$ transition of hydrogenic carbon. Further experiments and more complete theoretical modelling are planned to explore the physics of the excitation cross section and its energy dependence. 


\section{References}

${ }^{1}$ R. J. Fonck, Bull. Am. Phys. Soc. $\underline{32}, 1846(1987)$.

${ }^{2}$ R. P. Seraydarian, K. H. Burrell, N. H. Brooks, R. J. Groebner, and C. Kahn, R. Sci. Instrum. $\underline{57}, 155(1986)$.

${ }^{3}$ R. J. Groebner, W. Pfeifer, F. P. Blau, K. H. Burrell, E. S. Fairbanks, R. P. Seraydarian, H. St. John, and R. E. Stockdale, Nucl. Fusion 26, $543(1986)$.

${ }^{4}$ R. J. Jachnig, R. J. Fonck, K. Ide, and E. T. Powell, Rev. Sci. Instrum. $56,865(1985)$.

${ }^{5}$ G. Gammel, R. Kaita, R. Fonck, K. Jaehnig, and E. Powell, Rev. Sci. Instrum. 57, 1800(1986).

BM. Okabayashi, K. Bol, M. Chance, P. Couture, H. Fishman, R. J. Fonck, G. Gammel, W. Heidbrink, K. Ida, K. Jaehnig, G. Jahns, R. Kaita, S. Kaye, H. Kugel, B. LeBlanc, J. Manickam, W. Morris, G. Navratil, N. Ohyabu, S. Paul, E. Powell, M. Reusch, S. Sesnic, and H. Takahashi, 11 ${ }^{\text {th }}$ Internat. Conf. on Plasma Physics and Cont. Nuc. Fus. Res., IAEA-CN47/A-V-2, Nov. 13-20, 1986.

${ }^{\top}$ R. J. Fonck, D. S. Darrow, and K. P. Jaehnig, Phys. Rev. A 29, 3288(1984).

'R. C. Isler, L. E. Murray, S. Kasai, J. L. Lunlap, S. C. Bates, P. H. Edmonds, E. A. Lazarus, C. H. Ma, and M. Murakami, Phys. Rev. A 24, 2701(1981). 
${ }^{8}$ R. J. Goldston, D. C. McCune, H. H. Towner, S. L. Davis, R. J. Hawryluk, and G. L. Schmidt, J. Comput. Phys. 쓰, 61(1981).

${ }^{10}$ R. C. Isler, and R. E. Olsen, Phys. Rev. A (to be published). 


\section{FIGURE CAPTIONS}

Fig.1 The geometry of the neutral beamlines and the CHERS viewing sightlines on TFTR for the DNB and the heating beam(NB3).

Fig. 2 A toroidal rotation speed profile $v_{\phi}(r)$ as measured from two viewing locations. Circles represent the DNB data. Crosses represent the heating beam data. $R_{\text {plama }}=273$.

Fig.3a The spectral line components for the three neutral beam populations, with the sightline parallel to the beam direction and the dirertion of rotation. The resulting composite profile is shown (solid line). Also shown is the assumed Gaussian distribution for comparison (dotted line).

Fig.3b Same as 3 a but with beam direction perpendicular to sightline and rotation.

Fig.4 Charge exchange excitation coefficient for the $C^{+5}(n=8 \rightarrow 7)$ transition as a function of relative energy. Obtained from UDWA theory with full l-mixing imposed.

Fig.5 The $v_{\phi}(r)$ profiles from the DNB and the heating beam as corrected for the energy-dependent excitation rate coefficients. 


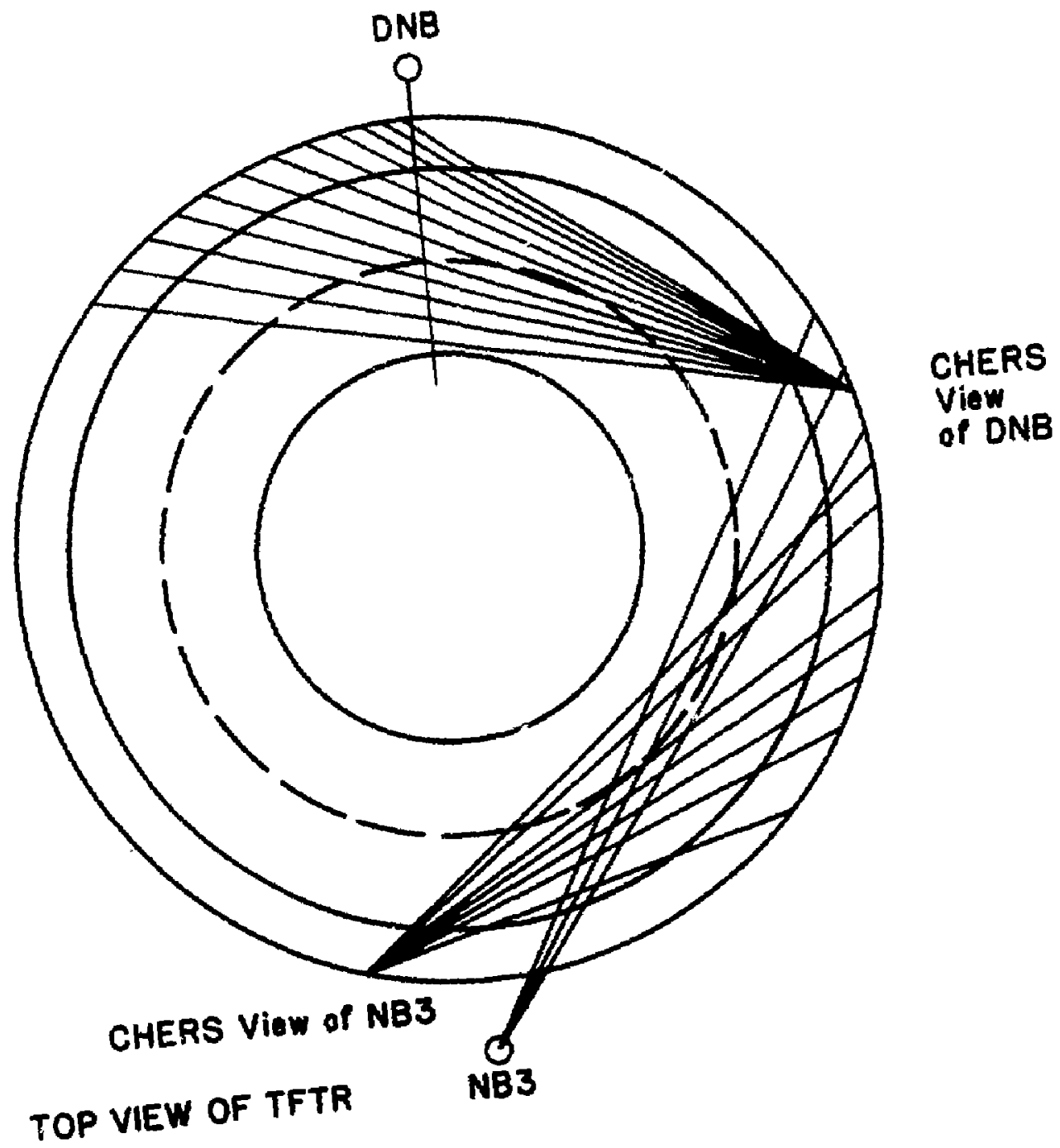

Eigure 1 


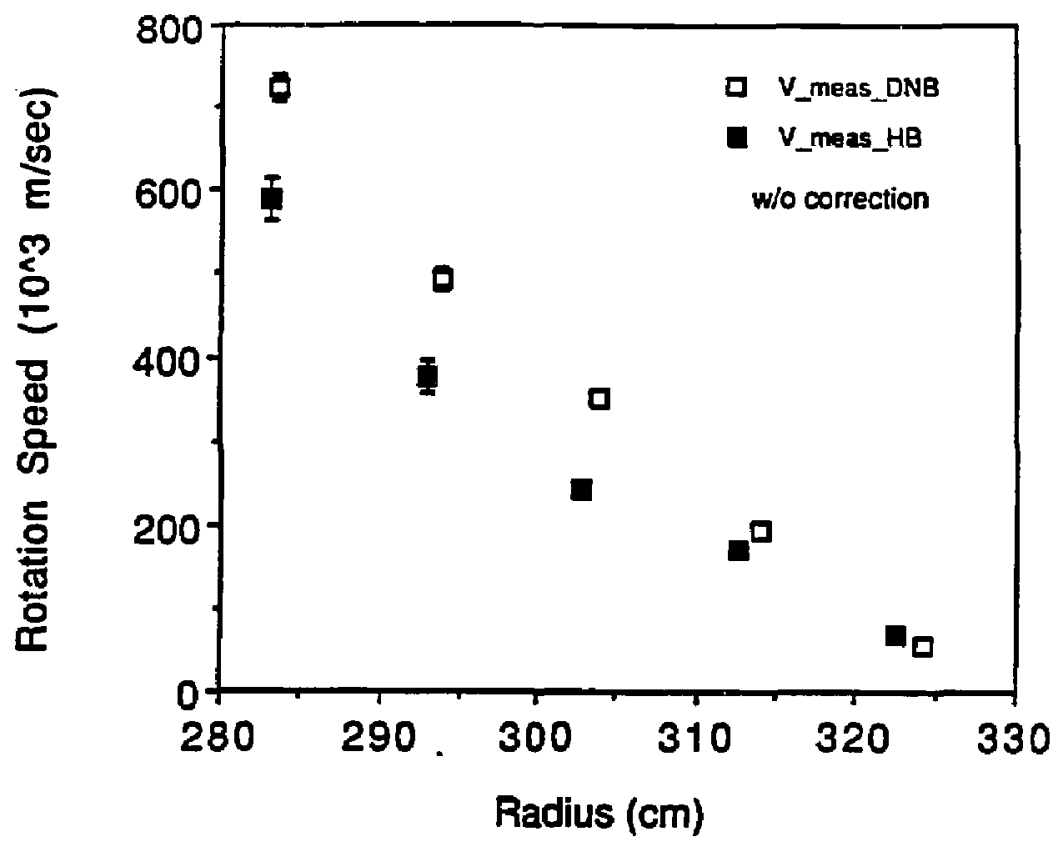

Flgute 2 


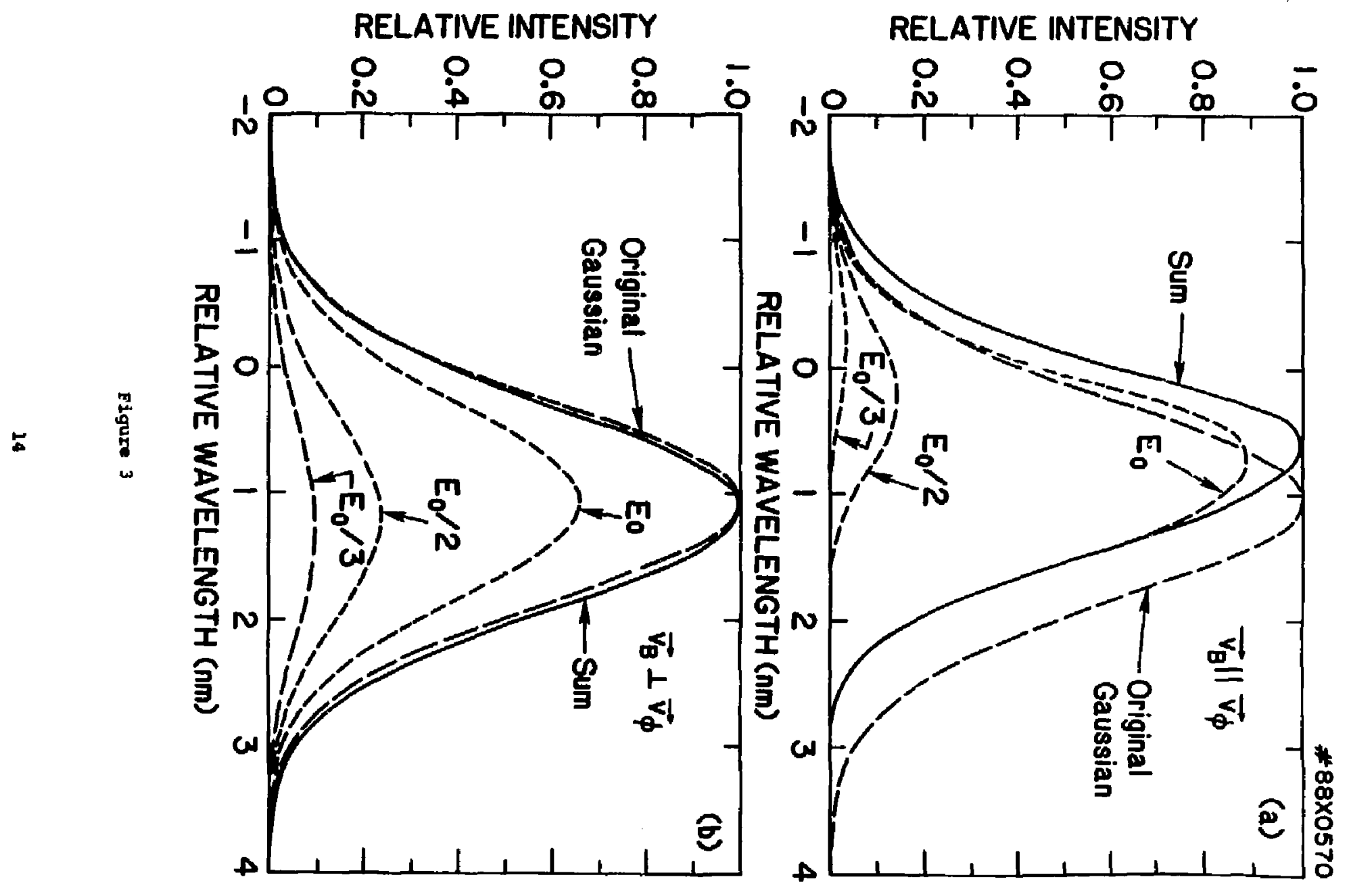




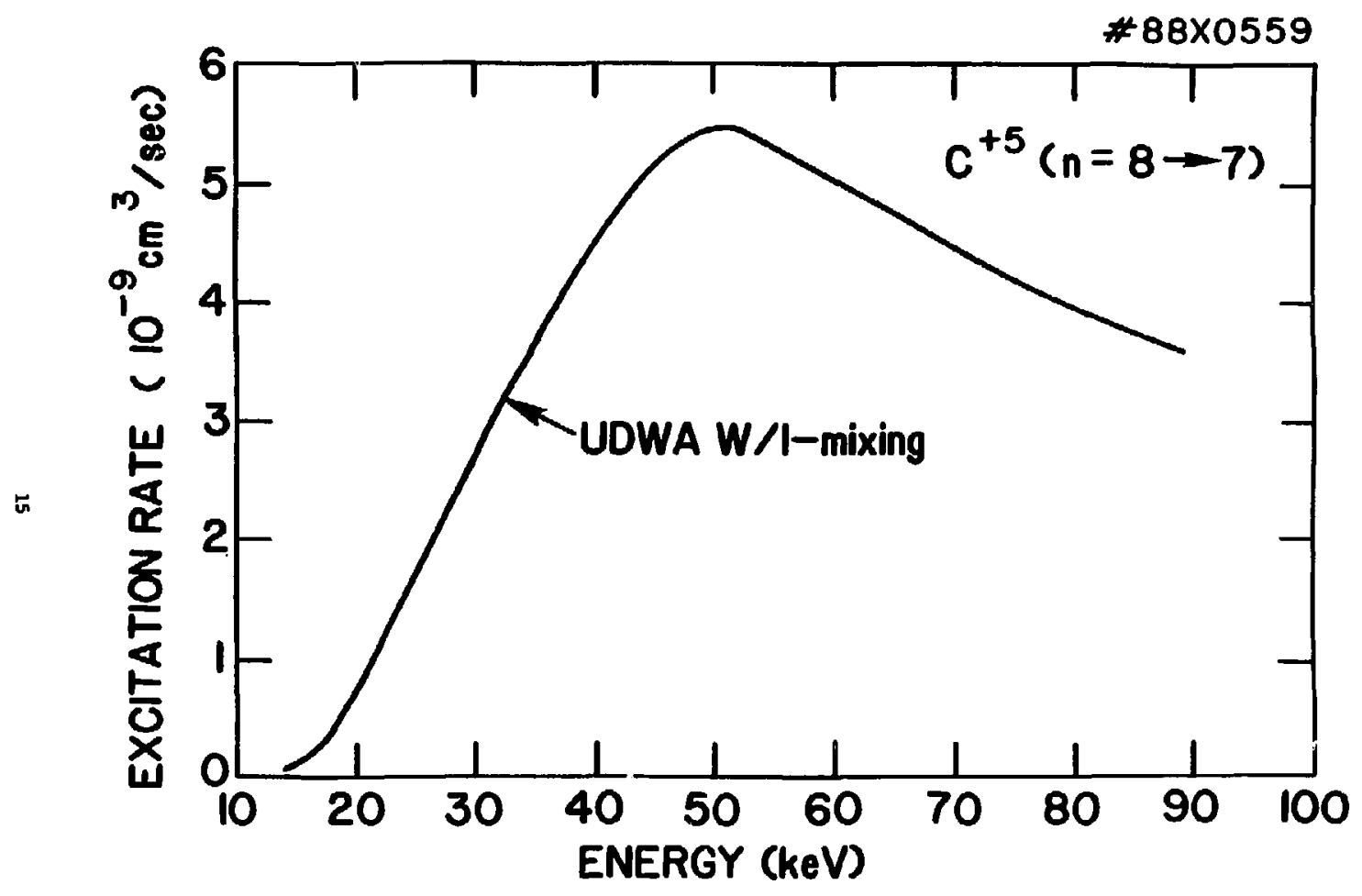

Figure 4 


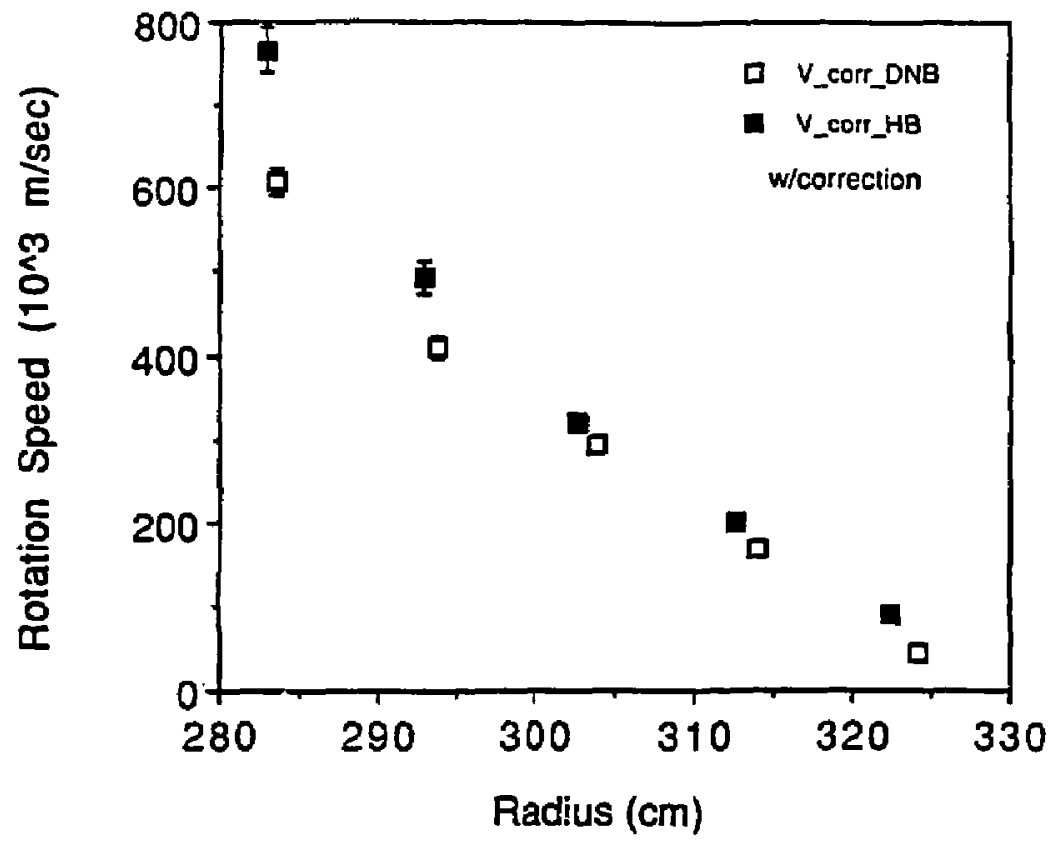

Figure 5 
Or. Frank J. Paoloni, Univ of Wol longong, AUSTRALIA Prof, M.H. Brennen, Univ Sydney, Australia

Plasmo Rosadech Lab.. Australian Nat. Univ., Australia Prof. I,R. Jones, filindars Unir., AUSTRALIA

Prof. F. Cad, Inst Theo Phys, AUstria

Prof. M. Heindler, Institut fur Theoratische Physik, AUSTRIA

M. Goossons, Astronomisch Instituut, BELGILN

Ecole Royale Militaire. Lab de Phys Plasmas, Belgiva

Comission-European, Og-XII Fusion Prog, BELGIUA

Prof. R. Bouciaue, Laboratoriun voor Natuurkunde, BELGILA

Dr. P.H. Sakanska, Instituto Fisica, BRMZIL

instituto De Pasquisas Espaclasi-IMPE, BRazIL

Docueants Offlce, Aroale Enargy of Canado Limited, Caruon

Dr. M.P. Bechynski, MP Technologies, Inc.., Curuon

Dr. H.M. Skarsgard, University of Saskatchaman, Cawon

Dr. H. Barnard, University of Britlsh Columbia, cawan

Prol. J. Toicheann, unir. of Montreal, CuwaA

Prof. S.R. Sreanlyasan, Unlverslty of Colgary, CNADA

Prol. Tudor W. Johnston, IRAs-Enargie, CuwDA

Dr. C.R. Jaess, Univ. of Alberta, CMwDA

Dr. Poter Lukac, Konenskeho Univ, CZECHOSLOVAKIA

The Librerian, Culhe Laboratory. ENCLAND

The Librarlan. Rutharford Appleton Laboratory. ERTLND

Mrs. S.A. Hutchinson, JET Library, ENGLAND

C. Mouttet, Lab. de Physlque des Milieux Ionises, frukce

J. Radet, CEN/CADARACHe - Bat 505, fanice

Univ. of loonnina, Library of Physics Oept. Geeece

Dr. Tan Mul, Acadery Bibliographic Ser., Hows kous

Preprint Library, Hungarian Acadeay of Selences, MULENRY

Dr. B. Dasgupta, Soha inst of Muel. Phys., IHDiA

Dr. P. Kaw. Institute for PI asea Research, INDIA

Dr. Philip Posenau, Israel Ingt. Tech, ISRAEL

Librarlan, Int'/ Ctr Theo Phys, ITALY

Prot. G. Rostagni, Univ Di Padova, ITALY

MIss Clelia De Palo, Assoc ELRATOH-EKEA, ITALY

BIbliateca, Instituto af fisice del Plasae, ITALY

Dr, H, Yauto, Toshiba fins \& Dav, JNPN

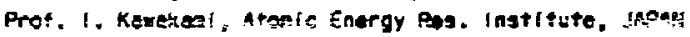

Prot. Myoji Mishikand, unJ of Hiroshino, JAPAN

Direc. Dept. Largo Tokenak Ras. JAER1, JNPAN

Prof. Satoshl Itoh, Kyushu University, JAPAN

Resoarch Info Conter, Megova University. JAPAM

Prof. S. Tanake, Kyoto University, JAPAM

Library, Kyoto University, JAPAN

Prof. :"huyuki Inowe, University of Tokyo, JAPAN

5. Mor $I$, JAEA!, JAPAN

Librarlan, Korea Advanced Energy Res. Institute, Korea

Prof. 0.1. Cho: , Mdv. Inst Sei \& Teeh, KOFEA

Prot. B.S. Liley. Univarsity of Walkato, REW ZEALAR

Institute of Plased Physics, PEOPLE'S REPUalic of CHIMh
2. Li, Southwest Inst. Physics, PEOPLE's aEPUalic of CHINA Prof. J.A c. Cabral, Inst Suporiar Tecnico, PoRTugal

De. Octavian Petrus, al I CUzA University, ROMANIA

Dr. Johan to Villiers, Fusion Studies, AEC, SO AFRICA

Prof. M.A. Hollbarg, University of Matal, SO AFRICA

C.I.E.M.A.T., Fusion Div. Library, SPAIN

Dr. Lennort Stentlo, University of UNEA, SWEDEN

Library, Royal Inst Tech, SWEDEN

Prof. Hans wilhelason, Chainers Univ Tach, SwEDEN

Cantre Phys des Plasmas, Ecola Polytesh Fod, SWITZERLANo

Bibliotheet, Fon-Inst Yoor Plasng-Fysica, THE NETHERLANOS

Dr. 0.0. Ryutov, SIbarian head Sel, USSR

Dr. G.A. Eliseev, Kurchatov Institute, USSR

Dr. V.A. Glukhikh, Inst Electrophysical ADoaratus, USSR

Dr. V.T. Tolok, Inst. Phys, Tech, USSR

Or. L.M. Kovrlzhnykh, Ingtitute Gon, Physics, USSA

Nuclaer Res. Establishment, Julich L†d.. W. GERaANY

Blbliothek, Inst. Fur Plasmaforschung, H. Gefatany

Dr. K. Schindlar, Ruhr Unlversitat Bochum, W. GERuWh

ASDEX Rosding Ra, IPP/Max-Plonck-inatitut iur

Plasmaphysik, M. GEFuwY

Librarian, Mok-Pianck Institut, W, Eefukry

Prof. R.K. Janov, Inst Phys, Yugoslavia 